\title{
BMJ Open Opinion leader empowered patients about the era of digital health: a qualitative study
}

\author{
Bertalan Meskó,, ${ }^{1,2}$ Nóra Radó, ${ }^{1}$ Zsuzsa Győrffy ${ }^{1,2}$
}

To cite: Meskó B, Radó N, Györffy Z. Opinion leader empowered patients about the era of digital health: a qualitative study. BMJ Open 2019;9:e025267. doi:10.1136/ bmjopen-2018-025267

- Prepublication history and additional material for this paper are available online. To view these files, please visit the journal online (http://dx.doi. org/10.1136/bmjopen-2018025267).

Received 6 July 2018 Revised 14 January 2019 Accepted 11 February 2019

D Check for updates

(c) Author(s) (or their employer(s)) 2019. Re-use permitted under CC BY-NC. No commercial re-use. See rights and permissions. Published by BMJ.

${ }^{1}$ The Medical Futurist Institute, Budapest, Hungary

${ }^{2}$ Institute of Behavioural

Sciences, Semmelweis

University, Faculty of Medicine, Budapest, Hungary

Correspondence to

Dr Bertalan Meskó;

berci@medicalfuturist.com

\section{ABSTRACT}

Objectives We aimed to explore the opinion leader empowered patients' relationship with their medical professionals, their experiences and beliefs about technologies, and how they see the future. We also attempted to determine whether technologies, the access to it or patient empowerment are the main driving forces behind these changes.

Design A qualitative interview study analysed with interpretative phenomenological analysis.

Setting All interviews were conducted and recorded individually with the same trained interviewer via a Skype call.

Participants The study is based on qualitative, semistructured interviews with 11 opinion leader empowered patients from six countries including UK, USA, Australia, Sweden, South Africa and Ireland.

Results We identified four superordinate themes emerging from e-patients' experiences: (1) impact of technology, (2) the meaning of empowerment, (3) the changing physicianpatient relationship and (4) expectations for the future. The relationship e-patients have with their physicians is based on efficient communication, proactivity, the desire for asking questions and the use of technologies. The interviews have shown that the rapid development of technology has fundamentally changed the lives of these e-patients, and technology eventually is transforming the physician-patient relationship into a partnership. Regarding the future of the physician-patient partnership, e-patients emphasised that change will rather be cultural than technological.

Conclusions The interviews have shown that cooperation between technology and healthcare is not enough on its own: the most decisive factor is the return of the human touch and reciprocal communication. All of these suggest that technology is an important ally in the 'renaissance of medicine' that starts to treat patients as it should have always had.

\section{INTRODUCTION}

The doctor-patient relationship, which is traditionally based on paternalism and hierarchy, has been significantly changing mainly due to the rising number of patients with chronic conditions and the digital era. During the last decades, the paternalistic interaction ${ }^{1}$ between physicians and patients has embraced a patient-centred approach, and both medicine and the social sciences

\section{Strengths and limitations of this study}

The main strength of this study is the approach to the personal experiences and thoughts of empowered patients who are considered opinion leaders worldwide about digital health and their relationship with their physicians.

- Our method allowed us to gain in-depth knowledge of underlying reasons and motivations of e-patients for being proactive in their care.

- The limitations of the qualitative method (interpretative phenomenological analysis [IPA]) include that the results cannot be generalised because of the small cohort size and the way participants were chosen.

- The method of IPA builds intensively on the interpreting process of the researchers which means the data obtained by them is already an interpretation made by the interviewee that has to be interpreted by them for the second time.

- Only e-patients speaking English were included in the study.

started to focus on the importance of questions of control, mutual participation and the new principles of the relationship. ${ }^{2-4}$

Various models of the current relationship have been discussed in the literature. ${ }^{5}$ Szasz and Hollender emphasised three basic models, two of them being paternalistic: activity-passivity and guidance-cooperation. ${ }^{6}$ The active-passive model is based on biomedical approaches and places the physician in total control of the treatment. In the guidance-cooperation model, the physician gives guidelines and expects the patient to cooperate and obey without question. The third model is mutual participation in which the physician makes an agreement with the patient about the treatment, especially in the case of chronic conditions. Emanuel and Emanuel assumed four models of the physician-patient relationship: paternalistic, informative, interpretive and the deliberative models. $^{7}$ 
Besides paternalism, another main model of the physician-patient relationship has developed since the 1990s. Charles $e t$ al described the shared decision-making model in which both the doctor and the patient are active in the decision process ${ }^{8}$. Both of them are involved and are participating in the treatment and the decision-making process, and they share information and express their treatment preferences.

Balint introduced the concept of 'doctor as a drug', according to which the quality of the relationship supplements the treatment. Thus, if the relationship is good, the prescribed drug or therapy is more effective. The physician-patient relationship works best when the patient receives more time, information and care from the specialist. $^{9}$

No matter what model we use, the transformation of the new relationship has been catalysed by the digital era. A revolution in information technology in the 1990s led to patient empowerment giving more access to medical information via the internet which eventually started shaping the job of physicians too. First, this meant that some patients became generally better informed and got more involved in the treatment and decision-making. ${ }^{10} 11$ It is entirely plausible for a patient today to have such a deep knowledge of their condition that it can even exceed the one of healthcare professionals. ${ }^{12}$

Thomas Ferguson used the expression 'empowered patient' or 'e-patient' first while creating a manifesto, now known as the e-patient white paper, before his untimely death in $2006 .{ }^{13}$ The paper was completed by his colleagues and published a year later. According to the definition, e-patients are health consumers participating fully in their medical care. This primarily means collecting information online or by any digital means about medical conditions influencing their own state and their relatives. The 'e' can stand for 'electronic', 'equipped', 'enabled', 'empowered', 'engaged' or 'expert'.

WHO defined empowerment as 'a process through which people gain greater control over decisions and actions affecting their health', ${ }^{14}$ which signifies a process on both the individual and the community level. That patient empowerment process is said to be based on four elements: (1) patients understanding their role; (2) adequate knowledge acquisition by patients for engaging with their healthcare provider; (3) patient skills and (4) the presence of a facilitating environment. ${ }^{14}$ In their literature review, Fumagalli et al established that empowerment is the combination of ability, motivation and power opportunities. ${ }^{15}$

The shifts in the doctor-patient relationship were further facilitated by the appearance of digital health in the 2010s. Digital health has become the cultural transformation of how disruptive technologies, which provide digital and objective data accessible to both caregivers and patients, lead to an equal level physician-patient relationship with shared decision-making and the democratisation of care. ${ }^{16}{ }^{17}$ It has helped spread the access to information and the use of technologies in disease and health management. ${ }^{18}$
Consequently, the ivory tower of medicine has first become more transparent then it is eventually becoming public. The access to medical studies, information, second opinion, peer support and digital health technologies has become more common. However, with only a few exceptions, ${ }^{19}$ physicians are not trained to be able to use new technologies due to gaps in the medical curriculum and are afraid of the loss of their prestige or power as patients step up.

All these lead to fundamental changes in the relationship between patients and physicians. Our aim was to explore this by observing what relationship empowered patients who are considered opinion leaders worldwide have today with their caregivers, what experiences and beliefs they have about technologies, and how they see the future.

We define and use the term opinion leader empowered patients as individuals who are well versed in a disease either as sufferers or care takers of individuals with chronic disorders and share their knowledge on the particular disease with others.' Also, 'a Patient Opinion Leader is a patient that suffers (or has suffered) from (a) chronic disease(s), either mental or physical, and that shares his/her knowledge about his/her condition and treatment on the Internet through blogs, videos, social media or community websites. ${ }^{20-22}$

We also attempted to determine whether technologies, the access to it or empowerment are the main driving forces behind these changes.

\section{METHODS}

\section{Participants}

The study is based on qualitative, semistructured interviews with opinion leader e-patients. ${ }^{20}$ Purposive sampling method was used based on the following inclusion criteria: self-proclaimed e-patients with globally popular online presence in English; optionally having publications in medical journals, books or essays about their views on healthcare; or have spoken at medical conferences about patient empowerment. We sent out 18 invitations by email and 11 participants accepted to be interviewed between 1 December 2017 and 28 February 2018. Table 1 shows the demographics and characteristics of the participants.

\section{Patient and Public Involvement}

For the development of the research question and outcome measurements, we based our analysis on existing examples. ${ }^{21-25}$ Patients were not involved in the design of the study or in the recruitment to and the conduct of the study. The most important results were returned to the interviewees when the qualitative analysis was completed to get feedback and comments for respondent validity. They also received the final manuscript. We have obtained written consent from participants to publish their personal information in the study.

\section{Interviews}

The semistructured interviews were conducted according to the following thematic blocks: the interview started 
Table 1 The demographics of interviewees

\begin{tabular}{|c|c|c|c|c|c|}
\hline $\begin{array}{l}\text { Code/name of } \\
\text { participants }\end{array}$ & Gender & Date of birth & $\begin{array}{l}\text { Degree of higher } \\
\text { education }\end{array}$ & Nationality & Medical condition \\
\hline I1 Alan Thomas & $\mathrm{M}$ & NA & No & UK & Ataxia \\
\hline I3 Dave deBronkart & M & 1950 & Yes & USA & Renal cell carcinoma \\
\hline 14 Hugo Campos & M & NA & Yes & USA & Hypertrophic cardiomyopathy \\
\hline I6 Kerri Morrone Sparling & $\mathrm{F}$ & NA & Yes & USA & Type 1 diabetes \\
\hline I7 Marie Ennis O'Connor & $\mathrm{F}$ & NA & Yes & Ireland & Breast cancer \\
\hline I8 Regina Holliday & $\mathrm{F}$ & 1972 & No & USA & Renal cell carcinoma (husband) \\
\hline I9 Renza Scibilia & $\mathrm{F}$ & NA & Yes & Australia & diabetes \\
\hline
\end{tabular}

with personal questions about medical history and demographics, continued with questions about the role of digital technologies, the physician-patient relationship, the patient-patient connections, the needs and feelings of e-patients, the challenges of medical education and prospects for the future (online supplementary materials). The interview guide was pilot tested and modified based on initial feedback. All interviews were conducted individually with the same trained interviewer via a Skype call lasting between 60 and $90 \mathrm{~min}$. The interviews were recorded on one device and audio recordings were transcribed by a professional transcriber. The interviewer checked the transcriptions for accuracy. The transcripts were then sent back to each participant for confirming their accuracy.

\section{Analysis}

Interpretative phenomenological analysis (IPA) was used as the method for analysing the conducted interviews. IPA has a strong background in phenomenological and hermeneutic traditions, which means a person-centred approach concentrating on an individual's interpretation of experience. ${ }^{19}$ The method allows the researcher to discern observations and treat the interviewed as experts. The IPA approach aims to explore and understand the experience as detailed as possible. ${ }^{26} 27$ IPA applies the idiographic method, which examines how individuals deal with a particular situation in their life. ${ }^{28}$

To ensure validity, two researchers conducted separate analyses of all the interviews and compared their results afterwards. The analyses were performed through the following steps: the primary coding was carried out using the inductive method. The two researchers (BM and $\mathrm{ZG}$ ) listened to the audio recordings of the interviews based on the recommendation of Rodham et al. ${ }^{29}$ Afterwards they performed the initial line-by-line coding of the verbatim transcribed interviews. Comments and preliminary themes were noted in the process. The Atlas. ti V.6.0. software was used for the qualitative analysis.

The most important emerging themes were defined based on the codes and their keywords. The theme was considered emerging if it appeared in at least half of the interviews. These themes were clustered according to conceptual similarities, and each cluster had a descriptive label. The main themes were sorted into different subthemes, and their connections were developed. Emerging themes were assigned with quotes from the interviews, while attempts were made to reveal the patterns of the themes of the individual interviews.

To ensure validity, both superordinate and subordinate themes were discussed and developed by the two researchers and the final code structure evolved. The final structure was determined in mutual agreement. The most important results were returned to the interviewees when the qualitative analysis was completed to get feedback and comments for respondent validity. ${ }^{30}$ Four of the 11 e-patients gave feedback and their suggestions were integrated into the final structure. ${ }^{31}$

\section{RESULTS}

We identified four superordinate themes emerging from e-patients' experiences: (1) impact of technology, (2) the meaning of empowerment, (3) the changing physicianpatient relationship and (4) expectations for the future. The list of superordinate themes and connected subordinate themes is illustrated in figure 1 .

\section{Theme I: the role of technology in the life of e-patients}

Participants expressed that the use of technological tools gives them a sense of safety and social support. Technology helps them monitor their health and keep in touch with their doctors and patient communities. They emphasised that the digital world means connection to 

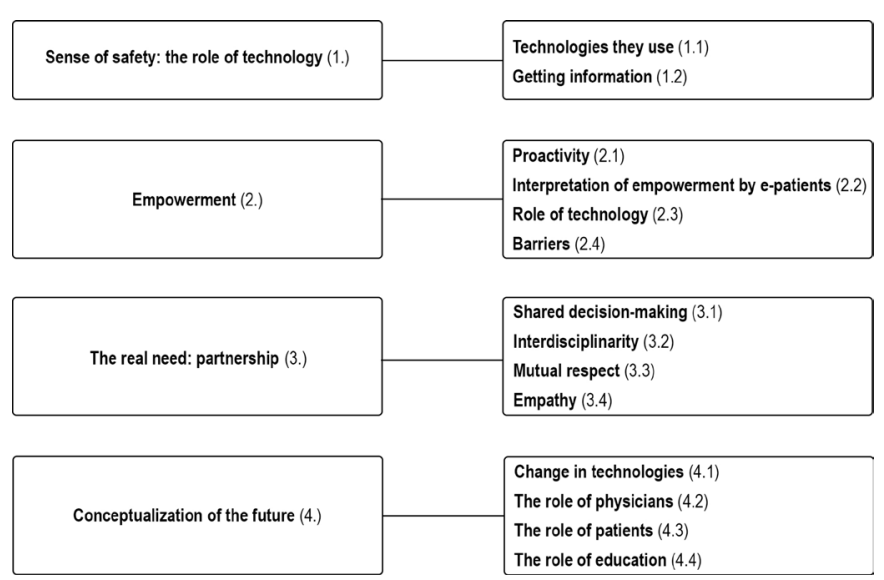

Figure 1 The list of superordinate themes and connected subordinate themes.

the outside world, therefore, online presence for a chronically ill person is decisive.

\section{E-patients use ordinary technologies}

The first subordinate theme focuses on technological devices. All participants use digital health technologies that can be divided into two main categories: communication tools (social media channels such as blogs and Twitter, websites, online forums, Open Notes, Skype and WhatsApp) and devices or sensors such as Fitbit, insulin pumps, glucose sensors or self-made continuous glucose monitors (figure 2).

'I am wearing a continuous glucose monitor, which is a sensor that I put onto my skin and goes through my skin and reads interstitial glucose levels every five min. So, I am able to look at my phone and see what my blood sugar is doing, what it has done and where it might be heading. So, it is not only giving me the results but it is giving me trend indications.' (I6)

\section{Communication and getting information}

In this subordinate theme, the practical impact of using digital health tools is emphasised. They use these technologies to connect to the world, share experiences and information with patients, physicians and other experts.

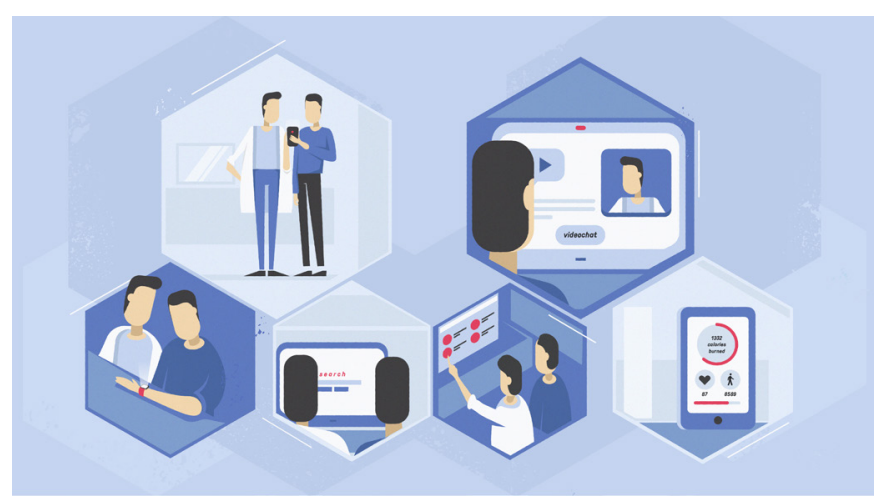

Figure 2 A summary of technologies the interviewed e-patients regularly use.
Most of them mentioned that a patient's blog contains important information for providers, patient communities and may be used in medical education too.

'I contacted about 20000 patients in the world for many, many different reasons. For me, one of the big things about the social media was the ability to connect to one patient to another.' (I5)

Experts such as researchers, physicians and patient advocates join some of these patient communities leading to a multidisciplinary point of view in the treatment and social support too. It creates contact with the physician, sending information to and building a relationship with them via digital technology. It can also help make decisions online in real time.

'I connected with this patient community where I got information and social support, which is important part of the patient's experience when they're isolated' (I3)

Technology provides access to relevant medical information which can be a key factor in the course of treatment, progression and further planning.

'In fact, twoyears ago, I saw a scientific article posted. It was a study about a medication that is used for cognition, it's a cholinesterase inhibitor, and this is used in the dementia patients to increase cognitional awareness and it was a study showing effects in Parkinson's on gait patterns, about how the person walked. About how taking this medication reduced gait difficulties. This was the study that was published the day before I saw it posted in a group or feed. I had exactly this problem with my gait. So, I emailed that article to my neurologist and asked if he could prescribe this medication. It was used in Parkinson but not for that indication. So, based on what I saw on my Facebook feed, I found information I needed to address one of my main issues. And I told my neurologist about that and he prescribed that medication.' (I10)

Self-monitoring through medical devices also contributes to deepening knowledge and effective health-sickness management.

Clearly having these tools that let people better track their glucose level, other parameters, and track of what they eat and exercise and other factors that affect their care. That is important. If we are able to, even via e-mail or via some apps, be in closer touch with the providers. (I2)

\section{Theme II: empowerment}

Proactivity is a major drive to empowerment

In this subtheme, participants discussed proactivity. To be proactive is the opposite of being patronised. They said that until now patients had been passive, only receiving 
medical care. The physician had been in the patriarchal, the 'doctor knows best' position.

Now the situation is changing: being a part of a movement of patients globally and speaking up for their rights and needs is a radical change in the status quo.

'Who are engaged and empowered, are not going to put up with doctors who are patronizing them'. (I2)

'The usual, traditional response for passive patients, who sit back, and hope things go well. An activated patient will say 'What can I do to help, what can I do to help the doctors, what can I do to help myself?'

\section{Empowerment means taking control of their health or disease management}

'Empowerment is about knowing your choices and being able to make your own choices.' (I9)

An empowered patient may become an active and equal partner in medical care and technology could facilitate this process. This is called participatory medicine:

'Participatory medicine is exactly parallel to participatory democracy, where the citizens are actively involved in running the community. And it's very much enabled by the internet because knowledge is power, and the internet enables the flow of knowledge.' (I3).

Empowered patients often have access to information, medical knowledge and their own health data. It is important for them to be in contact with other patients and become highly active, engaged, equipped and educated in this process. Sharing medical stories, pieces of advice, providing support to other patients, looking for new opportunities in treatment options are all characteristics of an empowered patient. They can learn the questions they need to ask and the confidence to ask those questions. They think that each patient can strive to be the expert of their own condition because of social media and technology in general.

'The duty of a patient is to find out about their condition and perhaps, especially in rare disease, share that knowledge to other patients to inform them, become more empowered patients.' (I1)

\section{Technology's role in the process of empowerment}

In this subtheme, participants mentioned that technological skills are important to empowerment. It is essential in this process that patients are curious, while doctors need bravery and willingness to make changes. They think medical professionals need to change their perception of medical support because now there's a sort of feeling that' I don't need a machine, I know myself,' although there is so much information that it's physically and mentally impossible for somebody to know everything. This is why participants think physicians need to recognise the values of technology and dare use it.
E-patients are happy to receive information from their physician, so they don't have to look for it online; at the same time, though, e-patients will often continue searching for additional knowledge. Implementing basic technologies such as texting a doctor, having a Skype call or using a mobile phone to receive blood results may improve connection between physicians and patients.

Technologies have a major potential to ease the process, but the real change in the relationship might come from physicians who need to be more comfortable with the technologies before they recommend it.

'Now that they have technology, it makes a little bit easier for them to listen and engage. It also helps the relationship because you are engaged more often.... you have to listen to the patient, you have to be curious, you have to let them engage and in technology it is one way of doing it, you can change anything.' (I5)

\section{Barriers}

Interviewees have pointed out that there are many obstacles to empowerment and that tackling these will not be easy. The barriers to empowerment include language skills (as speaking English has advantages); the lack of health literacy and digital literacy; as well as access to knowledge and resources (eg, digital tools and financial opportunities).

'The ability to know how to look for information, where to look for information, what type of information is trustworthy, what sources of information are trustworthy, how to separate the signal from the background noise, and really able to say this is not important, this is wrong information, this is not helping to me and only pick the bits of information that are useful, that are helpful and help them advance therapy or improve their care.' (I5)

\section{Theme III: the real need: partnership}

In this superordinate theme, participants discussed their needs as e-patients. The dominant theme for all of them was communication. ${ }^{1}$ E-patients require a different kind of physician-patient relationship as they need partnership with proper communication online and offline.

This partnership is a cultural change or paradigm shift: the conversation becomes reciprocal. Partnership also means that physicians and patients listen to each other, express their needs and desires clearly and have a common goal. Therefore, patients simply speaking to their physicians and physicians listening to them can radically change the physician-patient relationship. If physicians can listen, they can treat e-patients as an equal partner.

'I like to quote Susannah Fox on this; she thinks that the most radical and powerful part of digital health in the last decade has been people speaking to each other.' (I7) 


\section{Shared decision-making}

The importance of shared decision-making was a crucial point for all participants. The partnership is also based on shared decision-making. They stated that they would like to see all options and then hear the expert opinion of their physician about what they would choose. But then they make the decision together, weighing all costs and benefits. For shared decision-making, mutual trust is necessary. In this topic, the interviewees used the following expressions: being open, honest, knowing each other.

\section{Interdisciplinarity}

The nature of practising medicine is interdisciplinarity. What is new due to technologies is that patients also have teams around them consisting of family members and advocates, thus, it makes it a teamwork on both sides. ${ }^{32}$

'He (her physician) said 'I will look after you if you take as much care of your health as I will. I will teach you about the medicine; I will teach you what you need to know but you will teach me what it's like to be a patient and we will work together.' (I5)

'Over this weekend we have a DIY (CGM) group party with people who are already using it and with people who are just interested in starting, anyone can come. And a couple of health care professionals said that they want to come and be there. I think they want to see what ties this team, what is involved in that and they want to know the issues that people are already talking about.' (I9)

\section{Mutual respect is a critical component of partnership}

An important subordinate theme in the superordinate theme of needs was the respecting of both sides. They talked about proper communication with mutual respect. It requires respectful behaviour and encourages curiosity and sensitivity. Mutual respect must replace the passivity of both sides.

'I think patients and clinicians can see each other as human beings and respect the perspective of information, education that is coming from both sides.' (I7).

\section{Empathy}

It is necessary to be more empathetic to both parties.

'Patients have to empathize with doctors as well, like 'I understand you have seen fifty other patients before me today.' (I11)

When a patient is vulnerable both physically and emotionally, trust becomes a key issue of building a real partnership. The access to information helps balance the partnership, as for example, some physicians 'prescribe' online resources and smartphone apps they have evaluated. Empowered patients describe their physicians as experts who know where their expertise starts and ends and where it can be used.
Theme IV: the future of the physician-patient partnership

Interviewees are certain that patients' relationship with their caregivers is going to be a real partnership in which conversation is in the focus. Physicians will tell patients it is not just socially appropriate to ask questions but it is an important aspect to proactivity. Patients will prepare more for the visits and discussions.

'I am hoping that patients will prepare for the doctor's visit, they won't just tell their symptoms but they will have a list of questions so that they can get most out of their time and they can start taking charge more of the conversation rather than just sitting back and let the doctor say what it is you have, what treatment you can expect. So, patients will have some pre-research and they will have some informed questions.' (I7).

\section{Technologies}

Participants pointed out that a range of technologies from telemedicine to sensors and social media plays an important role in the change of the status quo. However, digital technology in the future will simplify but not replace contact between patients and caregivers. New technologies will just be a part of everyday care.

'I would love to see that the doctors have a website with frequently asked questions on it. I understand that the doctors worry that the patients will only email them, but I think the patients need that kind of insurance that if they have any questions, they can check the frequently asked questions. I think it is as simple as that. That saves time for the doctor at the consultation if the patients know that they can go on before and after onto the doctor's website and find the frequently asked questions.' (I7)

Technology could help reduce the burden of administration, thus increasing the time for personal interaction and enabling patient needs to be solved quickly via telecommunication technologies.

'Ten years from now every patient will be asked 'Do you want to come in? Do you want a video consult? Do you want your information through your mobile phone? What is the right thing for you?' (I5)

'A great hope is technology. We can gradually change by utilizing technology... People could do much cheaper with telehealth plus digital prescription than now. So, we should start leave behind the traditional medical model.' (I8)

\section{Physician of the future}

Physicians' time can be devoted to more important visits instead of being busy with things that a less qualified, less trained person could also do. At the same time, patients need to take responsibility.

'I hope that ten years from now doctors will be freer to occupy themselves with more difficult and complex tasks, complex diagnoses and not with tasks of 
common disease managements. Those tasks should be entrusted to the patient. And we free doctors to focus on complex diagnoses, complex treatment plans and the things that doctors should be concerned with. That's the role that patients should have and if we succeed in changing culture, everyone will understand that they need to take responsibility, they need to engage, and they do have a role to play in their own health and in health care not simply be a victim, or someone who has to take orders.' (I4)

Physicians' role will change too, becoming more like consultants or coaches. Physicians will act as guides in the jungle of information, technologies and health decisions.

'And instead of doctors saying do not Google your symptoms because you will feel sicker, they will actually support their patients and teach them how to Google and how to assess credibility and correctness on what they find. So that's what I hope, and I think that's what will happen.' (I10)

\section{Patient of the future}

Patient empowerment gives a new role to patients in this cultural shift and, in general, the e-patient phenomenon will become common.

'I believe empowerment is not limited to a bunch of patients who are able to. I hope it is a universal truth ten years from now.' (I6)

\section{The role of education}

Several participants mentioned that these changes must begin in medical and public education. Long-term cultural change in healthcare may only take place if it starts on the level of medical education.

\section{DISCUSSION}

We attempted to outline the views of opinion leader e-patients on the role of technology, empowerment, the physician-patient relationship and their vision of the future. Although many studies have focused on the empowerment phenomenon, the unique aspect of our research is the qualitative approach to the personal experiences and thoughts of opinion leader e-patients. ${ }^{33-35}$

These patients, who have authority to share their vision of care due to their reach, impact and influence on other patients' lives, as they are valid sources of questions and issues related to the future, all expressed that the coming decades of healthcare cannot be envisioned without putting technology in the spotlight.

The interviews have shown that the rapid development of technology has fundamentally changed the lives of these e-patients by providing more treatment options and facilitating the management of serious conditions. According to them, technology might be the new hope for reducing costs in care, solving the human resources crisis, and eventually transforming the physician-patient relationship into a partnership.

However, one of our key findings was that e-patients use communication tools and technologies such as search engines, Skype or Fitbit sensors, and they have not mentioned anything beyond the reach of an average consumer, therefore, being technology-savvy is helpful but is not a principal requirement for empowerment. As technology is just one element in this shift, e-patients do not expect their physicians to deal with complicated technologies because, in reality, it is not the case even with the most empowered patients.

Based on our results, proper physician-patient communication and a connection with their caregiver are the key components in the life of e-patients. Bensing et al summarised this in an apt way: 'Listen to the patients. They will tell you what they want and need'. ${ }^{36}$ Like Barham et al, we found that e-patients demand more time with their caregivers. ${ }^{37}$

The relationship e-patients have with their physicians is based on efficient communication, proactivity, the desire for asking questions and the use of technologies. Complementarily, they managed to find physicians who are partners in these. We suggest that these e-patients can serve as role models for patients who are currently not engaged in their own care.

However, as digital health technologies are becoming widespread, easier to use and more efficient, this will probably get more patients engaged in their care as the entry level to the use of technologies will get even lower. By helping physicians interact with patients better, providing means of health and disease management, finding medical information and getting access to patient data, technology has democratised the conversation and might further facilitate shared decision-making.

An e-patient has two main attributes: critical thinking and making informed decisions alone. ${ }^{35}$ Our interviewees agreed with this, claiming that patients have an obligation to inform themselves about their status and treatment options.

The role of responsibility also defines empowerment. The huge amount of available information enables patients to initiate and make decisions while giving them more responsibility. The foundation of the doctorpatient partnership model is that both the doctor's and the patient's performance is necessary for recovery. The doctor's role is to be an expert advisor, while the patient is an active, responsible 'coworker'. ${ }^{38}$

Patients' rights were established in the second half of the 20th century, and thanks to the empowerment movement, informed consent can now be complemented with shared decision-making with the patient. Charles et al emphasised both the physician and the patient to be involved in the decision-making process and information exchange, both the physician and the patient to express treatment preferences, and finally, the physician and patient to agree on the treatment decision. ${ }^{89}$ In this process, patients have to become more responsible 
for their treatment. ${ }^{40}$ For example, the development of patient decision aids has increasingly grown in Spain and currently, there are several of these materials available for patients with different diseases. ${ }^{41}$

The model of mutuality seems to be ideal for the physician-patient relationship while the fundamental features of practising medicine have not made it possible yet. Technologies only provided the initial motivation to change this and might further facilitate this shift from hierarchy to partnership. A patient-centred care model suggests that providers have to consider patients' needs, perspectives and experiences; offering opportunities to patients to provide and participate in their care and enhancing partnership $^{242} 43$

Patients' drive to empowerment lies in finding information and having communities. The interviewees all emphasised that trustworthy medical information (on reputable websites such as the one of their hospital, Mayo Clinic, etc) to be the primary choice before turning to the community. Technology is only the medium that helps build two-way trust that is the basis of partnership empowered patients are longing for.

Our results confirm the importance of education in becoming proactive: 8 of 11 e-patients have a higher education degree. This raises the questions whether the e-patient movement is a privilege for the well educated or it can become more widespread. The difference among healthcare systems can also be a difficult factor for empowerment. For example, the role of the 'conscious consumer' in private healthcare systems is obviously greater than in countries with socialised medicine, which might catalyse the e-patient movement. ${ }^{44-46}$ With regard to the prioritisation and regulation of digital technologies in healthcare, presumably, the more open the healthcare policy is, the more significant the e-patient movement will be. ${ }^{47}$

Access to information through technology provides an opportunity-one which e-patients are consciously using. In our study, a good example of this is the continuous monitoring of blood glucose levels, providing information, safety and conscious participation for the patientwhile the physician's physical presence is not required for the process. The technology opens a new model of medical treatment in which self-management is in the spotlight. $^{48}$

The interviewees emphasised that there are many obstacles in the way of empowerment. One of the main issues is accessibility, such as financial and educational disadvantages, which can be hindrances in the process of empowerment. Having health and digital literacy, speaking English, and sufficient financial resources are also essential. Besides the above-mentioned barriers, the importance of motivation, interest and the issues of trust, privacy, security and liability should also be considered.

While participants found the use of technologies advantageous in receiving better care, we have to address how the use of digital health technologies will affect patients' private information and whether laws such as Health
Insurance Portability and Accountability Act of 1996 (HIPAA) can help protect it. HIPAA is a legislation in the USA that provides data privacy and security provisions for safeguarding medical information. The proliferation of health data breaches in recent years caused by cyberattacks and ransomware attacks on health insurers and providers shed light on the issue whether such laws can protect the data of patients.

With the proliferation of digital health, the potential advantages of a preventive, accessible, personalised, augmented and humanistic healthcare system also pose serious threats to the individual and society. We hypothesise that an empowered patient will want to keep control over the use of their data as that is a key part of empowerment and current policies worldwide do not seem to be able to address this properly, except for a handful of examples in Denmark or the USA. ${ }^{49}$

Empowerment might also increase inequality among patients as those who have the skills to deal with online communication and technologies could get benefits over those who do not. Moreover, opinion leader e-patients are subject to the lobbying of pharma and healthcare companies similarly to their caregivers, which can influence their views. ${ }^{5051}$

Due to the above-mentioned phenomena, physicians of the 21st century face serious challenges. Improving knowledge and the adaptation of digital technologies have become crucial aspects of lifelong learning. ${ }^{52}$ The other part of the challenge is that informed and 'always on' patients are emerging who are questioning the fundamentals of medical paternalism, dominance and monopolism.

Regarding the future of the physician-patient partnership, e-patients emphasised that change will rather be cultural than technological. It is in accordance with the new 'biopsychosocial-digital' approach to health and disease ${ }^{53}$; as well as the meta-analysis of Calvillo $e t$ al: "current technology already allows establishing the first steps in the road ahead, but a change of attitude by all stakeholders (ie, professionals, patients and policy-makers) is required. ${ }^{25}$

As care will involve the use of digital health technologies, however, emphasis should be on how these shape the personal relationships patients have with their physicians while receiving care. We also expect to lose the e-patient expression over time as most patients will be empowered.

This study design has limitations though. As being considered an opinion leader is a broad category, and as only participants who speak English were approached, many potential opinion leader e-patients were out of the scope of the study. Also, it is challenging to decide whether patient empowerment is going to be widespread enough to be tested in many healthcare systems and cultures. One might argue that patient empowerment is an option only for privileged, educated patients who have access to technologies and information. There is also an ongoing debate about whether the transformation from patriarchy to partnership will be common or widen the 
gap between physicians and patients by creating more tension.

The limitations of the qualitative method (IPA) include that the results cannot be generalised because of the small size and the specially chosen sample. Another important theoretical limitation is that this method builds intensively on the interpreting process of the researchers, which means the data arriving to them is already an interpretation made by the interviewee that has to be interpreted by them a second time.

As each of the respondents expressed that it is necessary for reflection on changes in the physician-patient relationship to appear in medical training as well, this opens the way for new research areas. Therefore, we aim to continue our research with the description of the characteristics of the 21st century e-physicians to complement the views of e-patients on the present and the future of providing care.

\section{CONCLUSION}

We can argue that empowerment might have always been missing from healthcare because of the way the ivory tower was structured, and physicians were trained to become the ultimate experts of medicine. Communication and digital health technologies only facilitated the rise of empowerment and probably will further enhance it. However, interviews with opinion leader e-patients have shown that the cooperation between technology and healthcare is not enough on its own: the most decisive factor is the return of the human touch and reciprocal communication. All of these suggest that technology is an important ally in the 'renaissance of medicine' that starts to treat patients as it should always have had.

Acknowledgements The authors would like to express their gratitude to the participating e-patients. We are especially grateful to Szilvia Zörgő for her methodological advice.

Contributors BM and ZsGy designed the study, coded the data, performed the analysis and wrote the paper. $\mathrm{RN}$ designed the study and conducted the interviews. All authors read and approved the final manuscript.

Funding The authors have not declared a specific grant for this research from any funding agency in the public, commercial or not-for-profit sectors.

Competing interests None declared.

Patient consent for publication Obtained.

Ethics approval Ethical permission was obtained from the Ethical Committee of Semmelweis University, Budapest (No: 262/2017).

Provenance and peer review Not commissioned; externally peer reviewed.

Data sharing statement There are no data in this work.

Open access This is an open access article distributed in accordance with the Creative Commons Attribution Non Commercial (CC BY-NC 4.0) license, which permits others to distribute, remix, adapt, build upon this work non-commercially, and license their derivative works on different terms, provided the original work is properly cited, appropriate credit is given, any changes made indicated, and the use is non-commercial. See: http://creativecommons.org/licenses/by-nc/4.0/.

\section{REFERENCES}

1. Parsons T. The social system. New York: Free Press, 1951.
2. Engel GL. The need for a new medical model: a challenge for biomedicine. Science 1977;196:129-36.

3. Mead N, Bower P. Patient-centredness: a conceptual framework and review of the empirical literature. Soc Sci Med 2000;51:1087-110.

4. Organizations IA of P. Declaration on Patient-Centred Healthcare. London, UK, 2006.

5. Grünloh C, Myreteg G, Cajander Å, et al. "Why Do They Need to Check Me?" Patient Participation Through eHealth and the Doctor-Patient Relationship: qualitative study. J Med Internet Res 2018;20:e11.

6. Szasz TS, Hollender MH. A contribution to the philosophy of medicine; the basic models of the doctor-patient relationship. AMA Arch Intern Med 1956;97:585.

7. Emanuel EJ, Emanuel LL. Four models of the physician-patient relationship. JAMA 1995.

8. Charles C, Gafni A, Whelan T. Decision-making in the physicianpatient encounter: revisiting the shared treatment decision-making model. Soc Sci Med 1999;49:651-61.

9. Balint M. The Doctor, His Patient and the Illness. 2nd edn. Edinburgh: Churchill Livingstonge, 2000.

10. Elwyn G, Laitner S, Coulter A, et al. Implementing shared decision making in the NHS. BMJ 2010;341:c5146.

11. Makoul G, Clayman ML. An integrative model of shared decision making in medical encounters. Patient Educ Couns 2006;60:301-12.

12. Snow R, Humphrey C, Sandall J. What happens when patients know more than their doctors? Experiences of health interactions after diabetes patient education: a qualitative patient-led study. BMJ Open 2013;3: 003583.

13. Ferguson DT. Doc Tom [Internet]. http://www.doctom.com/.

14. WHO. Patient empowerment and health care. 2009 http://www.ncbi. nlm.nih.gov/books/NBK144022/.

15. Fumagalli LP, Radaelli G, Lettieri E, et al. Patient Empowerment and its neighbours: clarifying the boundaries and their mutual relationships. Health Policy 2015;119:384-94.

16. Meskó B, Drobni Z, Bényei É, et al. Digital health is a cultural transformation of traditional healthcare. Mhealth 2017;3:38.

17. Luk CY. The Impact of Digital Health on Traditional Healthcare Systems and Doctor-Patient Relationships: the case study of Singapore. In: innovative perspectives on Public Administration in the Digital Age [Internet]. 2018:143-67 https://www.igi-global.com/ chapter/the-impact-of-digital-health-on-traditional-healthcaresystems-and-doctor-patient-relationships/205099.

18. Riggare S. E-patients hold key to the future of healthcare. BMJ 2018;360:k846.

19. Mesko B, Györffy Z, Kollár J. Digital literacy in the medical curriculum: a course with social media tools and gamification. JMIR Med Educ 2015;1:e6.

20. Dicicco-Bloom B, Crabtree BF. The qualitative research interview. Med Educ 2006;40:314-21.

21. Bravo P, Edwards A, Barr PJ, et al. Conceptualising patient empowerment: a mixed methods study. BMC Health Serv Res 2015;15:252.

22. Barr PJ, Scholl I, Bravo P, et al. Assessment of patient empowerment--a systematic review of measures. PLoS One 2015; 10:e0126553.

23. Cerezo PG, Juvé-Udina ME, Delgado-Hito P. Concepts and measures of patient empowerment: a comprehensive review. Rev EsC Enferm USP 2016;50:667-74.

24. Herbert RJ, Gagnon AJ, Rennick JE, et al. A systematic review of questionnaires measuring health-related empowerment. Res Theory Nurs Pract 2009;23:107-32.

25. Calvillo J, Román I, Roa LM. How technology is empowering patients? A literature review. Health Expect 2015;18:643-52.

26. Smith JA. Beyond the divide between cognition and discourse: using interpretative phenomenological analysis in health psychology. Psychol Health 1996;11:261-71.

27. Brown JB, Stewart M. Evaluating Qualitative Research. Information mastery: Evidence-based family medicine. 1. London: BC Decker:129-32.

28. Smith JA-F, M P-I. Interpretative phenomenological analysis: theory, method and research. London: SAGE, 2009.

29. Rodham K, Fox F, Doran N. Exploring analytical trustworthiness and the process of reaching consensus in interpretative phenomenological analysis: lost in transcription. Int J Soc Res Methodol 2015.

30. Mays N, Pope C. Qualitative research in health care. Assessing quality in qualitative research. BMJ 2000;320:50-2.

31. Creswell JJ. Qualitative Inquiry and Research Design. Choosing Among Five Approaches. 2013.

32. Choi BC, Pak AW, Awp P. Multidisciplinarity, interdisciplinarity and transdisciplinarity in health research, services, education and policy: 
1. Definitions, objectives, and evidence of effectiveness. Clin Invest Med 2006;29:351-64.

33. Aujoulat I, d'Hoore W, Deccache A. Patient empowerment in theory and practice: polysemy or cacophony? Patient Educ Couns 2007;66:13-20.

34. Laugharne R, Priebe S. Trust, choice and power in mental health: a literature review. Soc Psychiatry Psychiatr Epidemiol 2006;41.

35. Anderson RM, Funnell MM. Patient empowerment: myths and misconceptions. Patient Educ Couns 2010;79:277-82.

36. Bensing J, Rimondini M, Visser A. What patients want. Patient Educ Couns 2013.

37. Barham V, Devlin RA, Wang X. Empowered patient or empowered physician: an analysis of the importance of the empowered patient in the health delivery system. Cah Sociol Demogr Med 2008;48:9-39.

38. Stanton J, Randal P. Developing a psychiatrist-patient relationship when both people are doctors: a qualitative study. BMJ Open 2016;6:e010216.

39. Pollard S, Bansback N, Bryan S. Physician attitudes toward shared decision making: a systematic review. Patient Educ Couns 2015;98:1046-57.

40. Loukanova S, Bridges J. Empowerment in medicine: an analysis of publication trends 1980-2005. Open Med 2008;3.

41. Perestelo-Perez L, Rivero-Santana A, Perez-Ramos J, et al. Shared decision making in Spain: current state and future perspectives. $Z$ Evid Fortbild Qual Gesundhwes 2011;105:289-95.

42. Epstein RM, Franks P, Fiscella K, et al. Measuring patient-centered communication in patient-physician consultations: theoretical and practical issues. Soc Sci Med 2005;61:1516-28.
43. Allen D, Scarinci N, Hickson L. The nature of patient- and familycentred care for young adults living with chronic disease and their family members: a systematic review. Int J Integr Care 2018;18:14.

44. Lupton D. The digitally engaged patient: Self-monitoring and selfcare in the digital health era. Social Theory \& Health 2013;11:256-70.

45. Boyer CA, Lutfey KE. Examining critical health policy issues within and beyond the clinical encounter: patient-provider relationships and help-seeking behaviors. J Health Soc Behav 2010;51:S80-93.

46. Timmermans $\mathrm{S}, \mathrm{Oh} \mathrm{H}$. The continued social transformation of the medical profession. J Health Soc Behav 2010;51:S94-106.

47. Bombard Y, Baker GR, Orlando E, et al. Engaging patients to improve quality of care: a systematic review. Implement Sci 2018;13:98.

48. Brynjolfsson E, Mcafee A. The Second Machine Age. Milken Institute Review: a journal of economic policy. 2014.

49. Meskó B, Györffy Z. Digital Health best practices for policy makers 2018 http://medicalfuturist.com/digital-health-best-practices-policymakers-free-report/.

50. Robotti SB. How Pharma Influences Some Patient Advocacy Groups: Medshadow Blog. 2017 https://medshadow.org/ medshadow_blog/pharma-patient-advocacy/.

51. Klopp E, Sydney Lupkin EL. Patient Advocacy Groups Take In Millions From Drugmakers. Is there a payback? https://khn.org/news/ patient-advocacy-groups-take-in-millions-from-drugmakers-is-therea-payback/.

52. deBronkart $D$. The patient's voice in the emerging era of participatory medicine. Int J Psychiatry Med 2018;53:350-60.

53. Ahmadvand A, Gatchel R, Brownstein J, et al. The biopsychosocialdigital approach to health and disease: call for a paradigm expansion. J Med Internet Res 2018;20:e189. 